\title{
Sociodemographic determinants of knowledge and attitude in the primary prevention of cervical cancer among University Tunku Abdul Rahman (UTAR) students in Malaysia: preliminary study of HPV vaccination
}

Maiza Tusimin ${ }^{1 *}$ D, Chek Lo Yee', Nur Zarifah Syahmi Abdul Razak', Mohamad Izwan Zainol', Halimatus Sakdiah Minhat ${ }^{2}$ and Zulida Rejali ${ }^{1}$

\begin{abstract}
Background: Cervical cancer is the third most common cancer affecting women around the world in which the Human Papillomavirus (HPV) is the one of the recognized causative agent affecting women health. In response to this health issue, the Malaysian government had officially implemented the HPV immunisation programme for secondary schoolchildren in 2010 at the age of 13 years old and above. The purpose of this study is to investigate the sociodemographic determinants of knowledge and attitude among students of Universiti Tunku Abdul Rahman (UTAR) towards the HPV vaccination programme.

Methods: A cross-sectional study was conducted using self-administered questionnaires, recruiting 374 UTAR's students as the respondents by using convenience sampling method. Respondents were categorized as having good/poor level of knowledge and positive/negative attitude towards HPV vaccination.
\end{abstract}

Results: Over half of the respondents were females (64.5\%) and the majority were aged 20 years old and below (55.8\%). Generally, 54.7\% of the total respondents had a high level of knowledge towards HPV vaccine while 57.5\% of the total respondents showed a negative attitude towards HPV vaccine. Female respondents aged 20 years old and below showed good knowledge (56.4\%) and a more positive attitude (55.8\%) towards HPV vaccine. Students from the Faculty of Medicine and Health Sciences (FMHS) exhibited higher knowledge (67.3\%) and positive attitude (62.4\%) as compared to the Faculty of Accountancy and Management (FAM) which showed only $32.7 \%$ of knowledge and $37.6 \%$ of positive attitude towards the HPV vaccination.

Conclusion: The majority of UTAR students possess good knowledge regarding HPV vaccination. Nonetheless, they demonstrated a negative attitude towards HPV vaccination, depicting the necessity to impart and further intensify the sense of health awareness among all students, especially among male students. The judicious use of social media apart from the conventional mass media should be an advantage as to enhance the practice of HPV vaccination among them and thereafter minimize the health and economic burdens of cervical cancer.

Keywords: Human papillomavirus (HPV) vaccination, Sociodemographic, Cervical cancer

\footnotetext{
*Correspondence: maiza@upm.edu.my

'Department of Obstetrics and Gynaecology, Faculty of Medicine and Health

Sciences, Universiti Putra Malaysia, 43400 Serdang, Selangor, Malaysia

Full list of author information is available at the end of the article
}

(c) The Author(s). 2019 Open Access This article is distributed under the terms of the Creative Commons Attribution 4.0 International License (http://creativecommons.org/licenses/by/4.0/), which permits unrestricted use, distribution, and reproduction in any medium, provided you give appropriate credit to the original author(s) and the source, provide a link to the Creative Commons license, and indicate if changes were made. The Creative Commons Public Domain Dedication waiver (http://creativecommons.org/publicdomain/zero/1.0/) applies to the data made available in this article, unless otherwise stated. 


\section{Key messages}

This research article mainly studied the sociodemographic determinants of knowledge and attitude towards HPV vaccination in the primary prevention of cervical cancer among students of Universiti Tunku Abdul Rahman (UTAR).

\section{Introduction}

\section{Background}

Worldwide, cervical cancer is one of the most common cancers in women [1]. In Malaysia, it is the third most common cancer affecting women and the fifth most common cancer for the entire general population [2]. Cervical cancer constitutes $8.4 \%$ of the total female cancers in this country [2]. The cervical cancer screening programme was established in Malaysia in the year 1969 as a secondary prevention measure of cervical cancer among the target group of women aged 20 to 65 years and many cancer awareness programmes have been launched over the years. Unfortunately, despite the intensive program, the number of cervical cancer had failed to reduce [3]. Therefore, the government has made a drastic measure by implementing free HPV vaccinations in 2010 for schoolchildren as a primary prevention measure.

In 2007, a National Immunisation Survey regarding HPV and HPV vaccination among adult women in the United States discovered that the awareness of HPV was $84.3 \%$ while the awareness of HPV vaccine was 78.9\% [4]. There was also a study conducted in China to determine the knowledge and attitude of HPV and HPV vaccines among women living in metropolitan and rural regions of China. Only $15 \%$ of the women in that study had heard of HPV. About $84.6 \%$ of the respondents were willing to be vaccinated if the vaccines were made available for them [5].

Several studies have been carried out to determine the level of awareness of HPV vaccination. For instance, in Melaka, $77.6 \%$ of secondary schoolgirls have heard about HPV vaccination. Meanwhile, a study among female university students showed that only $10.3 \%$ had heard of the HPV vaccine. A majority of them gained knowledge by newspapers, followed by friends and other public media such as magazines, television and radio. Only $48 \%$ of the students had the intention to receive HPV vaccination while the rest refused due to their concern regarding the safety and efficacy of the new vaccine. Therefore, this study was conducted to identify and focusing on the sociodemographic determinants of knowledge and attitude among students of Universiti Tunku Abdul Rahman (UTAR) towards the HPV vaccination programme.

\section{Methods}

\section{Study design}

This cross-sectional study was conducted among students of Universiti Tunku Abdul Rahman (UTAR), is a private university located in the Sungai Long Campus,
Selangor, Malaysia. The recruitment was carried out by distributing the questionnaire to the students. Only local undergraduate students were selected in this study. The questionnaire had been obtained from published article [6].

\section{Settings}

This study was carried out from March to September 2013.

\section{Participants}

This study was conducted among students of Universiti Tunku Abdul Rahman (UTAR) which in the Faculty of Accountancy and Management (FAM) and Faculty of Medicine and Health Science (FMHS). Only local undergraduate students aged 19 to 23 were selected whereas all international students were excluded in this study.

\section{Data collection Instruments}

Sociodemographic characteristics of the respondentsSeveral factors were identified under the sociodemographic section which included age, gender, parental income and faculties. The questionnaire was pre-tested prior to data collection. Knowledge and attitude towards HPV vaccination-A validated questionnaire was used with a Cronbach's coefficient alpha value of 0.92 . A previous study looked into the sociodemographic determinants of knowledge on HPV vaccination among Iranian women living in Malaysia. Score of ' 1 ' was given for any correct answer and ' 0 ' for any incorrect answer or those who answered 'do not know'. The median score of 6.0 for knowledge was used to categories good and poor levels of knowledge. Scores higher than the median were categorized as "good knowledge" while "poor knowledge" referred to scores lower than the median. A 4-point Likert scale was used to measure the attitude score, with ' 1 ' indicating strongly agree, ' 2 ' for somewhat agree, ' 3 ' for somewhat disagree and ' 4 ' for strongly disagree. An 'overall attitude score' was used for the purpose of analysis which referred to the actual total score of attitude from 18 questions for each respondent, divided by the expected total maximum score of attitude and multiplied by 100 . Scores between 0 to 47 were labeled as 'negative attitude' and 48 to 100 as 'positive attitude'.

\section{Statistical analysis}

All the data in this study were analyses by using the Statistical Package for the Social Sciences Version 21.0 which is predictive analytic software. Continuous data were described by mean, median and standard deviation while categorical data were described by percentage. The Chi-Square test was used to identify the association between the variable of categorical data and Kruskal-Wallis test was used for categorical data that were not normally distributed. The standard $p$ value in this study was $p=$ 
0.05 . Any p value smaller than $0.05(p<0.05)$ was considered significant and vice versa.

\section{Results}

Sociodemographic characteristics of the respondents

Table 1 shows the distribution of respondents according to their sociodemographic characteristics. Most of the respondents were 20 years old and below (55.8\%). Out of the 369 students, female had the highest frequency which was 238 students $(64.5 \%)$ and majority of the respondent were Chinese (91.9\%). The Faculty of Accountancy and Management (FAM) had 197 students (53.4\%), which contributed to the highest number of respondents compared to Faculty of Medicine and Health Science (FHMS). There was only one respondent who was married. The other 368 students (99.7\%) were single. The majority of the students' parental income was below than RM 3000 (63.1\%).

\section{Respondent's knowledge towards HPV vaccine}

Table 2 shows the distribution of respondent's knowledge towards HPV vaccination. The question that most respondents answered correctly ("Yes") was "What is the best age to get the vaccine?" where $75.9 \%$ of them responded correctly. On the other hand, the question that most respondents answered wrongly ("No") was "How many types of HPV vaccines are available?". Only $14.1 \%$ of the respondent's answered this question correctly. Out of the 12 questions, 7 questions were reported to have $50 \%$ or more

Table 1 Sociodemographic characteristics of the respondents

\begin{tabular}{|c|c|c|}
\hline \multicolumn{3}{|c|}{ Sociodemographic characteristics of the respondents } \\
\hline \multirow[t]{2}{*}{ Variables } & \multicolumn{2}{|c|}{ Respondent $(N=369)$} \\
\hline & Frequency $(n)$ & Percentage (\%) \\
\hline \multicolumn{3}{|l|}{ Age } \\
\hline$\leq 20$ years old & 206 & 55.8 \\
\hline$>20$ years old & 163 & 44.2 \\
\hline \multicolumn{3}{|l|}{ Gender } \\
\hline Male & 131 & 35.5 \\
\hline Female & 238 & 64.5 \\
\hline \multicolumn{3}{|l|}{ Ethnicity } \\
\hline Malay & 1 & 0.3 \\
\hline Chinese & 339 & 91.9 \\
\hline Indian & 21 & 5.7 \\
\hline Others & 8 & 2.2 \\
\hline \multicolumn{3}{|l|}{ Faculty } \\
\hline FMHS & 172 & 46.6 \\
\hline FAM & 197 & 53.4 \\
\hline \multicolumn{3}{|l|}{ Parents' income } \\
\hline$\leq \mathrm{RM} 3000$ & 233 & 63.1 \\
\hline$\geq$ RM 3000 & 136 & 36.9 \\
\hline
\end{tabular}

Table 2 Distribution of respondent's knowledge towards HPV vaccine

\begin{tabular}{|c|c|c|}
\hline \multicolumn{3}{|c|}{ Distribution of respondent's knowledge towards HPV vaccination } \\
\hline \multirow[t]{2}{*}{ Questions } & \multicolumn{2}{|c|}{ Frequency (\%) } \\
\hline & Yes* $^{*}$ & $\mathrm{No}^{*}$ \\
\hline How many types of HPV vaccine are available? & $52(14.1)$ & $317(85.9)$ \\
\hline How much is it per dose? & $83(22.5)$ & $286(77.5)$ \\
\hline What is the best age to get the vaccine? & $280(75.9)$ & $89(24.1)$ \\
\hline \multicolumn{3}{|l|}{$\begin{array}{l}\text { How many times women should be vaccinated } \\
\text { against HPV? }\end{array}$} \\
\hline & $249(67.5)$ & $120(32.5)$ \\
\hline Men would be benefit from HPV vaccination? & $129(35.0)$ & $240(65.0)$ \\
\hline \multicolumn{3}{|l|}{$\begin{array}{l}\text { Do you think HPV vaccine is more useful for } \\
\text { women who have multiple sexual partners? }\end{array}$} \\
\hline & $207(56.1)$ & $162(43.9)$ \\
\hline \multicolumn{3}{|l|}{$\begin{array}{l}\text { Do you think women who received of HPV } \\
\text { vaccine do not need to do regular pap smear? }\end{array}$} \\
\hline & $204(55.3)$ & $165(44.7)$ \\
\hline Can HPV vaccine cause genital warts? & $119(32.2)$ & $250(67.8)$ \\
\hline Can HPV vaccine cure cervical cancer? & $189(51.2)$ & $180(48.8)$ \\
\hline Can HPV vaccine cure genital warts? & $145(39.3)$ & $224(60.7)$ \\
\hline Can pregnant women take HPV vaccine? & $198(53.7)$ & 171 (46.3) \\
\hline
\end{tabular}

*yes: correct answer, ${ }^{*}$ no: wrong answer and no information

respondents who managed to answer them correctly. The other five questions were not answered correctly by the majority of the respondents.

\section{Association between sociodemographic characteristic and knowledge}

Table 3 shows the association between sociodemographic characteristic and knowledge involved in this study. The $p$-value $(p<0.05)$ showed a significant association. This study showed female students having good knowledge (127.9\%) compared to male students (72.1\%) towards the HPV vaccination. Besides, the knowledge of HPV vaccination in both faculties of FAM and FMNS also showed the differences. FAM contributed the higher knowledge (111.1\%) compared to FMHS which is only 88.9\% towards the HPV vaccination knowledge.

\section{Association between sociodemographic characteristics and attitude}

Table 4 shows the association between attitude and the sociodemographic characteristics involved in this study. The $p$-value $(p<0.05)$ showed a significant association.

\section{Discussion}

This study demonstrated that most of the respondents aged 20 years old and below possessed good knowledge regarding HPV vaccination (56.4\%). This had been agreed by Al-Naggar et al. (2010) with a study conducted 
Table 3 Association between sociodemographic characteristic and knowledge towards HPV vaccination

\begin{tabular}{|c|c|c|c|c|c|c|}
\hline \multirow{3}{*}{$\begin{array}{l}\text { Sociodemographic } \\
\text { characteristic }\end{array}$} & \multicolumn{4}{|c|}{ Knowledge towards HPV vaccine } & \multirow[t]{3}{*}{ Total } & \multirow{3}{*}{$\begin{array}{l}p- \\
\text { value }\end{array}$} \\
\hline & \multicolumn{2}{|c|}{ Poor } & \multicolumn{2}{|c|}{ Good } & & \\
\hline & $n$ & $\%$ & $n$ & $\%$ & & \\
\hline \multicolumn{7}{|l|}{ Age } \\
\hline$\leq 20$ years old & 92 & 55.1 & 114 & 56.4 & 111.5 & $0.796^{\mathrm{a}}$ \\
\hline$>20$ years old & 75 & 44.9 & 88 & 43.6 & 83.5 & \\
\hline \multicolumn{7}{|l|}{ Gender } \\
\hline Male & 70 & 41.9 & 61 & 30.2 & 72.1 & $0.019^{\mathrm{a}}$ \\
\hline Female & 97 & 58.1 & 141 & 69.8 & 127.9 & \\
\hline \multicolumn{7}{|l|}{ Parents income } \\
\hline$\leq \mathrm{RM} 3000$ & 127 & 76.0 & 106 & 52.5 & 128.5 & $0.001^{\mathrm{a}}$ \\
\hline$>$ RM 3000 & 40 & 24.0 & 96 & 47.5 & 71.5 & \\
\hline \multicolumn{7}{|l|}{ Faculty } \\
\hline FMHS & 36 & 21.6 & 136 & 67.3 & 88.9 & $0.001^{\mathrm{a}}$ \\
\hline FAM & 131 & 78.4 & 66 & 32.7 & 111.1 & \\
\hline
\end{tabular}

${ }^{a}$ Chi-square test, ${ }^{\text {b}}$ Kruskal Wallis test, ${ }^{*} p$-value $<0.05$ show significant association

among the general population showed that the majority of the respondents aged 17 to 30 had a good level of knowledge (82.4\%) regarding HPV vaccine [7]. The younger population possessing good knowledge on HPV vaccination is parallel with the government's effort since 2010 where the National HPV Immunisation Programme was launched for secondary schoolgirls. In addition, the NGOs have been actively involved in promoting HPV vaccination targeting the youth population.

Table 4 Association between sociodemographic characteristics and attitude towards HPV Vaccination

\begin{tabular}{|c|c|c|c|c|c|c|}
\hline \multirow{3}{*}{$\begin{array}{l}\text { Sociodemographic } \\
\text { characteristic }\end{array}$} & \multicolumn{4}{|c|}{ Attitude towards HPV vaccine } & \multirow[t]{3}{*}{ Total } & \multirow[t]{3}{*}{$p$-value } \\
\hline & \multicolumn{2}{|c|}{ Negative } & \multicolumn{2}{|c|}{ Positive } & & \\
\hline & $n$ & $\%$ & $n$ & $\%$ & & \\
\hline \multicolumn{7}{|l|}{ Age } \\
\hline$\leq 20$ years old & 109 & 51.4 & 97 & 61.8 & 113.2 & $0.047^{a}$ \\
\hline$>20$ years old & 103 & 48.6 & 60 & 38.2 & 86.8 & \\
\hline \multicolumn{7}{|l|}{ Gender } \\
\hline Male & 92 & 43.4 & 39 & 24.8 & 68.2 & $0.001^{\mathrm{a}}$ \\
\hline Female & 120 & 56.6 & 118 & 75.2 & 131.8 & \\
\hline \multicolumn{7}{|l|}{ Parents income } \\
\hline$\leq \mathrm{RM} 3000$ & 139 & 65.6 & 94 & 59.9 & 125.5 & $0.262^{a}$ \\
\hline$>$ RM 3000 & 73 & 34.4 & 63 & 40.1 & 74.5 & \\
\hline \multicolumn{7}{|l|}{ Faculty } \\
\hline FMHS & 74 & 34.9 & 98 & 62.4 & 97.3 & $0.001^{\mathrm{a}}$ \\
\hline FAM & 138 & 65.1 & 59 & 37.6 & 102.7 & \\
\hline
\end{tabular}

${ }^{a}$ Chi-square test, ${ }^{b}$ Kruskal Wallis test, ${ }^{*} p$-value $<0.05$ show significant association
The majority of the female respondents had a significantly good knowledge towards HPV vaccination (69.8\%) as compared to the male respondents in this study. Similar findings were revealed in a study by O'Flarity (2012) where $83.0 \%$ of female respondents knew more about the HPV vaccine [8]. According to Ji et al. (2007), there was an association found between gender and knowledge towards HPV vaccine [9]. The different result between this study and the previous study is due to the difference in the distribution of respondents by ethnicity where in this study was not normally distributed as the majority of the respondents were Chinese.

This study found that there was a significant association between knowledge towards HPV vaccination at the $p$ value of $0.001(p<0.05)$. Similar findings were reported in the other studies $[10,11]$. In addition, there was a significant association between parental income and level of knowledge on HPV vaccine. Respondents with low parental income showed good knowledge on HPV vaccination $(52.5 \%)$ while parents with high income showed a poor knowledge regarding HPV vaccine (47.5\%). In contrast, a similar study done among Malaysian women [12] found that respondents with a high family income had a good knowledge towards HPV vaccine.

Besides that, this study showed a significant association between age and attitude towards HPV vaccination as the $p$-value was $0.049(p<0.05)$. Respondents at age of 20 years old and below showed a positive attitude towards HPV vaccination as compared to the respondents aged beyond 20 (61.8\% vs. $38.2 \%)$. A study among Malaysian women [12] also reported that there was significant association between attitude towards HPV vaccination and age. Respondents of the lower age range (19-30 years old) showed the highest percentage of positive attitude towards HPV vaccine $(65.6 \%)$ while the higher age range $(>40$ years old) had a higher percentage of negative attitude towards HPV vaccine (68.0\%) [12]. Therefore, the lower the age, the higher the attitude towards HPV vaccine. According to gender difference, the female students showed a positive attitude towards HPV vaccination as compared to males. More than half of the respondents with positive attitudes were females (75.2\%). A study among Korean adults [13] also found that adult females had a more positive attitude than adult males. This is due to less information about HPV vaccine related to male diseases. Most of the male respondents thought that HPV vaccine was just for women and related to cervical cancer.

In this study, the majority of the respondents with positive attitude towards HPV vaccine were respondents whose parents' incomes were less than RM 3000, which was $59.9 \%$. Another study showed that a family income of less than RM2000 had a more positive attitude $(66.7 \%)$ when compared to a family income of more than RM 4000 (56.3\%) [13]. Respondents with a lower socioeconomic 
status were more acceptable towards the HPV vaccine. In addition, this study reported that respondents with good knowledge were higher from FMHS (67.3\%) when compared to FAM (32.7\%). Another study also reported that a medical education had a direct correlation with a high level of knowledge where $87.7 \%$ of them had heard about HPV [14]. This is because medical students should know more about HPV vaccine when compared to students of other programmes since medical students will have more chance to get to know HPV vaccine during their classes and lectures. Most of the students with positive attitudes were from FMHS (62.4\%) when compared to FAM (37.6\%). This may be because the students from FMHS should know more and have a higher level of knowledge towards HPV vaccine. When these students understand the benefit of HPV vaccine and the consequence of HPV, they should have a more positive attitude towards HPV vaccine.

\section{Strengths and limitations}

This study has contributed valuable facts and figures regarding HPV in relation to knowledge and attitude demonstrated among the students. However, the limitations of this study included the utilisation of Universiti Tunku Abdul Rahman (UTAR) as a private university and an imbalance in the demonstrated distribution of ethnicity and religion of the sample population. Besides that, due to the time duration of research, there is no assessment of vaccination status or intention could be done.

\section{Conclusion}

The level of knowledge of UTAR students was reasonably high. Gender and parents' income were associated with the knowledge of HPV vaccine while age and gender were associated with attitudes towards HPV vaccine. Nonetheless, a minority of male students still exhibited negative attitude towards HPV vaccination, depicting the necessity to impart and further intensify the sense of health awareness among all students. The judicious use of social media apart from the conventional mass media should be an advantage as to enhance the practice of HPV vaccination among them and thereafter minimize the health and economic burden of cervical cancer.

\footnotetext{
Abbreviations

FAM: Faculty of Accountancy and Management; FMHS: Faculty of Medicine and Health Science; HPV: Human papillomavirus; NGOs: Non-government organisation; UTAR: Universiti Tunku Abdul Rahman
}

\section{Acknowledgements}

We would like to express our extended gratitude to all those who gave us the opportunity to conduct this research. We gratefully acknowledged the President of Universiti Tunku Abdul Rahman, Ir. Prof. Dato' Dr. Chuah Hean Teik, Vice President of R\&D and Commercialisation, Prof. Dr. Ir. Lee Sze, Dean of Faculty of Accountancy and Management, Asst. Prof. Dr. Ong Seng Fook and Dean of Faculty of Medicine and Health Sciences, Prof. Emeritus Dr. Cheong Soon Keng. This work was supported by the Faculty of Medicine and Health Sciences, Universiti Putra Malaysia and Universiti Tunku Abdul
Rahman. We gratefully acknowledged The International Society for Gynaecologic Endoscopy (ISGE) World Congress 2016.

\section{Authors' contributions}

MT had designed the study, provided the concept and definition of intellectual consent, contributed to the literature search, experimental studies, data collections, statistical analysis, manuscript preparation, editing and reviewing. CLY, NZS and MIZ had contributed to the literature search, experimental studies, data collections, statistical analysis, and manuscript preparation, editing and reviewing. HSM had contributed to the study concepts, design and manuscript preparation while ZR had contributed to manuscript preparation. All authors have contributed and are in agreement with the content of the manuscript. We have no conflicts of interest to disclose.

*Maiza Tusimin (MT); Chek Lok Yee (CLY); Nur Zarifah Syahmi Abdul Razak (NZS); Mohamad Izwan Zainol (MIZ); Halimatus Sakdiah Minhat (HSM); Zulida Rejali (ZR). All authors read and approved the final manuscript.

\section{Funding}

This research received no specific grant from any funding agency in the public, commercial or not-for-profit sectors.

\section{Availability of data and materials}

Maiza Tusimin (MT) on behalf of all authors affirmed that the manuscript is an honest, accurate and transparent account of the study being reported. No important aspects of the study have been omitted and any discrepancies from the study as planned have been explained. The full dataset is available from the corresponding author maiza@upm.edu.my.

\section{Ethics approval and consent to participate}

This study was approved by the University Research Ethics Committee, Universiti Putra Malaysia (UPM/TNCPI/RMC/1.4.18.1 (JKEUPM)/F1, 06/18/2013). Full permission to conduct the survey in Universiti Tunku Abdul Rahman (UTAR) has been obtained (UTAR/Survey/June 2013). The written informed consent had been obtained from all the participants.

\section{Consent for publication}

Not applicable.

\section{Competing interests}

The authors declare that they have no competing interests.

\section{Author details}

${ }^{1}$ Department of Obstetrics and Gynaecology, Faculty of Medicine and Health Sciences, Universiti Putra Malaysia, 43400 Serdang, Selangor, Malaysia.

${ }^{2}$ Department of Community Health, Faculty of Medicine and Health Sciences, Universiti Putra Malaysia, 43400 Serdang, Selangor, Malaysia.

Received: 10 October 2018 Accepted: 11 October 2019

Published online: 05 November 2019

\section{References}

1. Ahmedin J, Bray F, Center MM, Ferlay J, Ward E, Forman D. Global cancer statistic. CA Cancer J Clin. 2010;61:69-90.

2. National Cancer Registry. Report Malaysia Cancer Statistics-Data and Figure 2007. Ministry of Health 2007.

3. Low WY, Wong LP, Wong YL, et al. Knowledge and awareness of cervical cancer and screening among Malaysian women who have never had a pap smear: a qualitative study. Singap Med J. 2009:50:49-53.

4. Euler GL, Jain N, Lu P, Markowitz L, Shefer A, Yankey D. Human papillomavirus (HPV) awareness and vaccination initiation among women in United States, National Immunization Survey. Eur J Obstet Gynecl Reprod Biol. 2007:148:90-5.

5. Li J, Wang JB, Liang H, Qiao YL, Li LK, Ma JF, et al. Knowledge and attitudes about human papillomavirus (HPV) and HPV vaccines among women living in metropolitan and rural regions of China. Vaccine. 2009;27:1210-5.

6. Wang $H$, Long L, Cai H, Wu Y, Xu J, Shu C, Wang P, Li B, Wei Q, Shang X, Wang $X$, Zhang $M$, Xiong $C$, Yin P. Contraception and unintended pregnancy among unmarried female university students: a cross-sectional study from China. PLoS One. 2015;10(6):e0130212. https://doi.org/10.1371/ journal.pone.0130212. 
7. Al-Naggar RA, Al-Jashamy K, Chen R. Perception and opinion regarding human papillomavirus vaccination among young women in Malaysia. Asian Pac J Cancer Prev. 2010;6:1515-21.

8. O'Flarity K. Knowledge and attitudes regarding the human papillomavirus and HPV vaccine among college students: a gender comparison study honors. Honors Theses Paper. 2012;50.

9. Ji KO, Ming KL, Hwa Y, Eun HL, Shin HR. Awareness of and attitude towards human papillomavirus infection and vaccination for cervical cancer prevention among adult males and females in Korea: a nationwide interview survey. Vaccine. 2007;28:1854-60.

10. Minhat HS, Mustafa J, Sarabi S. Sociodemographic determinants of knowledge on HPV vaccination among Iranian women living in Malaysia. Acad J Cancer Res. 2013;6(1):8-12.

11. Wong LP, Sam IC. Ethnically diverse female university students's knowledge and attitude toward human papillomavirus (HPV), HPV vaccination and cervical cancer. Eur J Obstet Gynecol Reprod Biol. 2010;148:90-5.

12. Al-Dubai SAR, Alshagga MA, Al-Naggar RA, Al-Jashamy K, Baobaid MF, Tuang CP, Abdul Kadir SY. Knowledge, attitude and barriers for human papillomavirus (HPV) vaccines among Malaysian women. Asian Pac J Cancer Prevention. 2010:11.

13. Oh JK, Lim MK, Yun EH, Lee EH, Shin HR. Awareness of and attitude towards human papillomavirus infection and vaccination for cervical cancer prevention among adult males and females in Korea: a nationwide interview survey. Vaccine. 2010;28:1854-60.

14. Lenselink CH, Schmeink CE, Mechers WJG, Massuger LFAG, Hendriks JCM, Hamont DV, et al. Young adults and acceptance of the human papillomavirus. Public Health. 2008;122:1295-301.

\section{Publisher's Note}

Springer Nature remains neutral with regard to jurisdictional claims in published maps and institutional affiliations.

Ready to submit your research? Choose BMC and benefit from:

- fast, convenient online submission

- thorough peer review by experienced researchers in your field

- rapid publication on acceptance

- support for research data, including large and complex data types

- gold Open Access which fosters wider collaboration and increased citations

- maximum visibility for your research: over $100 \mathrm{M}$ website views per year

At $\mathrm{BMC}$, research is always in progress.

Learn more biomedcentral.com/submissions 